\title{
TANITMA: TOKYÜREK, HACER: Altun Yaruk Sudur IV. Tegzinç (Karşılaştırmalı Metin Yayını). Kayseri 2015,718 s.
}

\section{Arzu DEVECI'1}

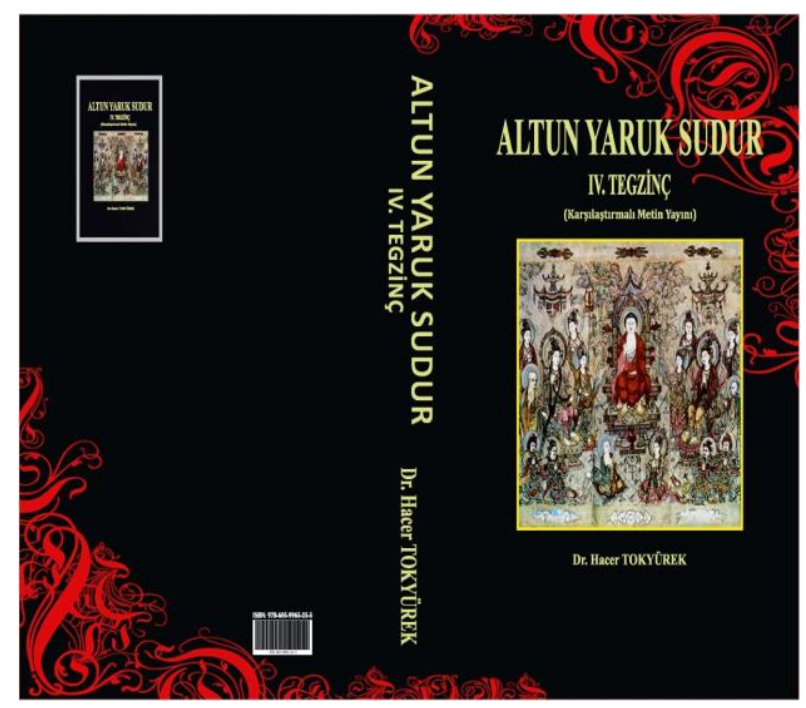

Muhterem hocamız HACER TOKYÜREK, ilk baskısı 2015 yllında yayınlanan Altun Yaruk Sudur IV. Tegzinç (Karşılaştırmah Metin Yayımı) adlı eserinde Altun Yaruk Sūtra (ET. altun öplüg y(a)ruk yaltrklig kopda kötrülmiš nom eligi athg nom bitig)'nın altıncı bölümünü ihtiva eden, Bodhisattva'ların erdemlerinin ele alındığ IV. kitabın karşılaştırmalı yayınını bizlerin faydasina sunmuştur.

718 sayfadan oluşan hacimli eser, altı ana bölümden oluşmaktadır. Eser, yazarın kaleme almış olduğu "ÖN SÖZ" (s. 5) yazısından sonra gelen ve yedi alt başlığa ayrılan “1. GİRİŞ” (s. 7-26) bölümüyle başlamaktadır. Eserde, "1. GIRISS" bölümünden sonra gelen “2. BERLİN METIN PARÇALARI” (s. 27-257), "3. ST. PETERSBURG (RM) ASIL METIN” (s. 258-466), “4. TÜRKIYE TÜRKÇESINE AKTARIMI” (s. 467-506), “5. AÇIKLAMALAR" (s. 507-642) ve “6. DiZiN” (s. 643-718) bölümleri bulunmaktadır.

"Giriş" bölümünde, Altun Yaruk Sūtra'nın, henüz elimizde mevcut olmayan "Suvarṇabhāsottamasūtrendrarāja, Suvarnaphāsottamasūtrrarāja, Suvarṇaprabhāsottama"2 adlı asıl Sanskritçe metinden Yİ JìNG (義淨) 3 tarafından Çinceye aktarıldı̆̆ı ve de ŞíNKO ŞÄLİ TuTUy'un onu Çince metinden Uygurcaya tercüme ettiği bilgileri verilmiştir (s. 7). ${ }^{4}$ Giriş bölümünün "1.1. Altun Yaruk Sūtra" adlı alt başlı̆̆ında Çince metnin, St. Petersburg nüshasının ve Berlin parçalarının arasında önemli farklılıklar olduğunu göstermek amacıyla iki örnek cümle ele alınmış ve aralarındaki farklar açıklanmıştır. Misal olarak St. Petersburg nüshasında Sanskritçe kelimeler mevcutken Berlin fragmanlarında bulunmamasının muhtemel iki sebebi şu şekilde açıklamıştır: Bu farklılıklar ya sūtranın aynı metinden değil, farklı zamanlarda farklı nüshalardan çevrilmiş olmasından ya da Sanskritçe kelimelerin müstensih tarafından sonradan eklenmesinden kaynaklı olabilir (s. 8).

IV. kitap, altıncı bölümün Berlin fragmanlarının EHLERS 5 ve RASCHMANN ${ }^{6}$ tarafindan kataloglanmış olduğu ve bunların U ile kayıtlı 196, Mainz ile kayıtlı 62 olmak üzere toplamda

1 Georg-August Üniversitaet, Turkologie Doktora Öğrencisi, deveci_arzu@hotmail.com

2 Uçar, ERdem: Uygurca Altun Yaruk Sudur IX. Tegzinç. Diplomatik Neşir Usûlüyle Yayını Tercüme Açıklamalar ve Dizin. İzmir 2013. (Dinozor Kitabevi Yayınları.)

3 s. 7'de şu kaynaklara atıfta bulunulmuştur: NoBEL, JoHANNEs: Suvarn aprabhāsottamasūtra. Das Goldglanz-sūtra. Ein Sanskrittext des Mahāyāna-Buddhismus. Nach den Handschriften und mit Hilfe der Tibetischen und Chinesischen Übertragungen. Leipzig 1937, XIII-XV; UÇAR, ERDEM: Uygurca Altun Yaruk Sudur IX. Tegzinç. Diplomatik Neşir Usûlüyle Yayını Tercüme Açıklamalar ve Dizin. İzmir 2013, 12.

4 Şu kaynağa atıf yapılmıştır: ÖlmeZ, MenmeT: Altun Yaruk III. Kitap (= 5. Bölüm). Ankara 1991, 7.

5 EHLERS, GERHARD: Alttürkische Handschriften. Teil 2. Das Goldglanzsūtra und der buddhistische Legendenzyklus Daśakarmapathāvadānamālā. Depositum der Preußischen Akademie der 
INTRODUCTION: TOKYÜREK, HACER: Altun Yaruk Sudur IV. Tegzinç (Karşılaştırmalı Metin Yayını). Kayseri 2015, 718 s. / A. Deveci (p. 127-132)

258 (önlü arkalı 516) parçadan oluştuğu kaleme alınmıştır. Ele alınan bölümün RADLOVMALOV'da ise 201 ve 344. sayfalar arasında bulunduğu belirtilmiştir (s. 8).

Budist Jātaka'lar, öğrencilerin hocalarına sordukları sorular ve buna verilen cevaplar şeklinde devam eder. Buradaki Budist edebiyatın meşhur Mahāyāna sūtrasının IV. kitabı da Bodhisattva'nın Buddha'ya sorduğu sorular ve onun verdiği cevaplardan oluşur. Bu sūtranın asıl amacı canlıların Pāramită’ları "en yüksek, zirve, doğum ölüm kıyısı olan bu kıyıdan diğer kıyıya yani Nirvāna’ya geçişlerin (s. 9)”; yani erdemlerin yeri ve önemini kavrayarak doğru ve tam bilgiyi elde etmeleri olduğu anlatılır (s. 9).

“1.2.1. Pāramitā ve Türleri” adlı bölümde Sanskrit parama kökünden türetilmiş Pāramitā kelimesinin anlamından ve türlerinden bahsedilmiştir. Pāramitäların anlaşılması için kaynak kitap olabilecek eserin bu bölümünde, ayrıntılı olarak açıklanan on Pāramitä’nın adları söyledir (s. 9-15):

1. Dāna Pāramitā "Sadaka Erdemi” (s. 9-10)

2. Ś́laPāramitā "Ahlâkî Davranış Erdemi” (s. 10-11)

3. Kṣānti Pāramitā "Sabır, Tahammül Erdemi” (s. 11-12)

4. Virya Pāramitā "Gayret ya da Enerji Erdemi” (s. 12)

5. Dhyāna Pāramitā "Derin Düşünce Erdemi” (s. 13)

6. Prajñā Pāramitā "Bilgi Erdemi” (s. 13)

7. Upāya Pāramitā "Doğru Yöntem Uygulama Erdemi” (s. 14)

8. Praṇidhāna Pāramitā "Bodhi Olma Erdemi" (s. 14)

9. Bala Pāramitā "Güç Erdemi” (s. 15)

10. Kṛtyānuṣthāna-jñānaPāramitā "Bilgelik Erdemi” (s. 15)

Yukarıda sıralanan on Pāramitā, canlıları Samsāra'dan yani "doğum ölüm döngüsünden" kurtarıp Nirvāṇa’ya ulaştırmak için uygulanması gereken prensiplerdir (s. 9).7

Dördüncü kitapta bulunan iki manzum parça "1.2.2. IV. Kitapta Yer Alan Manzum Parça” (s. 15-16) başlıklı bölümde yer almaktadır. Bunlardan bir tanesi daha uzun, kuralsız bir şekilde mısra sonu kafiyesine sahip ve Buddha'nın Bodhisattva tarafından övüldüğü; diğeri ise daha kısa, çok fazla şiir özelliği göstermeyen bir manzum parçadır.

Giriş bölümünün "1.3. IV. Kitap Üzerine Yapılan Çalışmalar” (s. 16-17) adlı alt başlı̆̆ında, Altun Yaruk Sūtra IV. kitap üzerine, 1913 yllından günümüze kadar yapılan araştırmaların özeti yapılmış ve ÖLMEZ ${ }^{8}$, KAYA ${ }^{9}$, AYAZLII ${ }^{10}$, ÇETíN ${ }^{11}$ gibi araştırmacıların konuyla ilgili çalışmalarının kaynakçalarına ve araştırma tarihçesi bölümlerine atıfta bulunulmuştur.

Wissenschaften (Staatsbibliothek Preußischer Kulturbesitz, Berlin). Stuttgart 1987. (Verzeichnis der Orientalischen Handschriften in Deutschland 13, 10.)

6 Raschmann, Simone-Christiane: Alttürkische Handschriften. Teil 6. Berliner Fragmente des GoldglanzSütras. Teil 2: Viertes und fünftes Buch. Beschrieben von Simone-CHristiane Raschmann. Stuttgart 2002. (Verzeichnis der Orientalischen Handschriften in Deutschland 13, 14.)

7 Şu kaynaklara gönderme yapılmıştır: SOOTHILl, WILLIAM EdWARD / LEWIS Hodous: A Dictionary of Chinese Buddhist Terms with Sanskrit and English Equaivalents and a Sanskrit-Pali Index. London 1937, 301a, 250b; TOKYÜREK, HACER: Eski Uygur Türkçesinde Budizm ve Manihaizm Terimleri. Kayseri 2011. (Erciyes Üniversitesi, Sosyal Bilimler Enstitüsü, Yayımlanmamış Doktora Tezi), 238.

8 Ölmez, Menmet: Altun Yaruk. III. Kitap (= 5. Bölüm). (Suvarṇ aprabhâsasûtra). Ankara 1991. (Türk Dilleri Araştırmaları Dizisi 1), 8-11. 
TANITMA: TOKYÜREK, HACER: Altun Yaruk Sudur IV. Tegzinç (Karşılaştırmalı Metin Yayını). Kayseri 2015, 718 s. / A. Deveci (127-132. s.)

“1.4. Yöntem ve Teknikler” (s. 17-19) başlıklı alt bölümde sistematik ve düzenli şekilde, eser yayına hazırlanırken kullanılan teknik ve özellikler hakkında bir özet sunulmuştur. Eseri yayıma hazırlayan HACER TOKYÜREK, IV. kitabın hem Berlin fragmanlarına hem de St. Petersburg nüshalarına başvurarak dokümansal ve tenkitli/eleştirel bir neşir yaptığını belirtmiştir. Bahsettiğimiz değerli eserin tanıtmasını kaleme alan MELİKE UÇAR'ın ${ }^{12}$ da sıralı bir şekilde listelediği yöntemler şu şekildedir:

- St. Petersburg nüshasında bulunmayan bölümler Berlin fragmanlarına göre tamamlanmıştır. St. Petersburg nüshasının yazı çevirimi yapılırken St. Petersburg ve Berlin nüshasında bulunan ve bulunmayan parçalar dipnotlarda verilmiştir.

○ Berlin parçalarında kırmızı mürekkeple yazılmış kelimeler koyu yazılmıştır.

- Aşağıdaki misaldeki gibi birkaç parçadan oluşan Berlin fragmanlarının sağına metnin hangi parçalardan çevrildiği ve metnin RADLOV-MALOV'daki yeri verilmiştir. Metin eğer sadece bir Berlin parçasından oluşuyorsa sadece RADLOV-MALOV'daki yeri yazılmıştır:

$$
\begin{aligned}
& \text { “...] b[u ärü]r altınč [... mainz 500/1, U3176/1 } \quad \text { RM 211/9-10 } \\
& \text {...] p[////]r ”ltynč” (s. 18) }
\end{aligned}
$$

- St. Petersburg nüshasının harf çevirisi ve yazı çevirimi yapılırken, RADLOVMALOV'un 201-344. sayfaları arasında yer alan metnin hangi sayfada yer aldığı alt simge “201" şeklinde gösterilmiştir. Müellifin verdiği ooo1 sayısıyla St. Petersburg nüshası sıralanmaya başlamış ve daha sonra St. Petersburg nüshasında bulunan satır numarası "01" şeklinde gösterilmiştir. Daha sonra üst simge şeklinde metnin sağına metnin TAisHō'daki yeri ve onun Çince çevirisi eklenmiştir. Uygurca metinde karşıllğı olmayan Çince ifadeler koyu renkle yazılmıştır.

- Dipnot verilirken kelimelerin altı çizilmediyse bu dipnotta sadece dipnot işaretinden önce gelen kelimeden bahsedileceğini göstermektedir. Eğer birden fazla kelimenin altı çizilmişse bu altı çizilen bütün kelimelerle ilgili bilgi verileceği anlamına gelir.

- Metinde, kelimelerin tam olarak okunamayan harflerinin eğik yazıldı ̆̆ belirtilmiş ve işaret bölümünde verilen simgelerin kullanım yerleri ayrıntılı bir şekilde anlatılmıştır.

$\mathrm{Bu}$ bölümden sonra gelen "1.5. İşaretler” (s. 20) başlığında kullanılan işaretlerin listesi verilmiştir. Bunlara ikilemeler için kullanılan " 2 ” işareti eklenebilir.

Eserin “1.6. Kısaltmalar” (s. 20-21) bölümünde eklenmemiş olan aşağıdaki kısaltmaların eklenmesi eserin geniş kaynakçasından faydalanacak Türkologların çalışmalarını hızlandıracaktır.

9 KaYA, Ceval: Uygurca Altun Yaruk. Giriş, Metin ve Dizin. Ankara. (Atatürk Kültür Dil ve Tarih Yüksek Kurumu Türk Dil Kurumu Yayınları 607), 38-43.

$10 \quad$ AyAZLI, ÖZlem: Altun Yaruk Sudur VI. Kitap. Karşılaştırmalı Metin Yayını. İstanbul 2012. (Atatürk Kültür Dil ve Tarih Yüksek Kurumu Türk Dil Kurumu Yayınları 1051), 7-12.

11 Çetin, Engin: Altun Yaruk Yedinci Kitap. Berlin Bilimler Akademisindeki Metin Parçaları Karşılaştırmalı Metin, Çeviri, Açıllamalar, Dizin. Adana 2012, 20-21.

12 UÇAR, Melike: "Yrd. Doç. Dr. Hacer Tokyürek'in Altun Yaruk Sudur IV. Tegzinç Adlı Eseri Üzerine”. Uluslararası Türkçe Edebiyat Kültür Eğitim Dergisi 4/2 (2015), 826-836. 
ADAW Abhandlungen der Deutschen Akademie der Wissenschaften zu Berlin

AKPAW Abhandlungen der Königlich Preußischen Akademie der Wissenschaften

APAW Abhandlungen der Preußischen Akademie der Wissenschaften

UAJb Ural-Altaische Jahrbücher

“1.7. Kaynakça ve Eser Kısaltmaları” (s. 21-26) başlıklı ayrıntılı bölümde eserin hazırlanmasında kullanılan kaynak kitaplar kısa başlıklar şeklinde sıralanmıştır. Kaynakçalar hazırlanırken şu hususlarda birlik sağlanmalıdır: Müellif isminden sonra parantez içinde yayın tarihinin verilip verilmesi, eser isminden sonra ".” ya da "," konması, basım yeri ve yayınevinin yazılış sırası ve arasına ":" ya da "," konmasında aynı kural esas alınmalıdır. BT 25 ve (Berliner Turfantexte; II) örneğinde olduğu gibi künyenin sonuna kitabın hangi seride yayınlandığı yazılırken birlik sağlanmalıdır.

"IV. Kitap Üzerine Yapılan Çalışmalar” bölümünde bahsedilen ve sehven yazılmayan RACHMATI'nin eseri kaynakçaya Bibliographie alttürkischer Studien'deki gibi eklenebilir: ARAT, GABDUL RAŞID RACHMATI: Türkische Turfantexte. VII. Mit sinologischen Anmerkungen von Dr. WOLFRAM EBERHARD. Berlin 1937. (Abhandlungen der Preußischen Akademie der Wissenschaften. Philosophisch- historische Klasse 1936: 12.)

Kaynakçaya şu değişiklikler eklenebilir:

Ayazlı 2012: $\quad$ Ankara < İstanbul

Barutçu 1988: Sthiramati’nin Vasubandhu'nun Abhidharmā Kosavardi Şastirtaki Çınkirtü Yöröglerning Çingürüsi'nden Üç İtigsizler < Sthiramati'nin Vasubandhu'nun Abhidharmakośaśāstra'sına yazdığı tefsirin ETü. tercümesi. Abidarim ḳınlıg koşavarti şastirtaḳı çınkirtü yörüglerning kingürüsi'nden üç itigsizler

Beer 2003: $\quad$ Chicago < Chicago and London, handbook $<$ Handbook

Burnouf 2010: Introduction of The < Introduction of the, Th e University < The University, Buff etrille $<$ Buffetrille

Buswell 2003: $\quad 2003<2004$

Clauson 1972: Türkish $<$ Turkish

Ehlers 1987: Daśakarmaparhāvadānamālā < Daśakarmapathāvadānamālā

ER 1987: $\quad$ Newyork < New York

Gabain 1954: Brahmischrift < Brāhmīschrift

Gabain 2000: TDK Yayınları < AKDTYK. TDK Yayınları (ilk çevirisi 1988 yılındadır)

Laut 2003: $\quad$ Sprachund Kulturkontakt < Sprach- und Kulturkontakt

Laut 2013: $\quad$ sayfa numarası 18-37, basım yeri Venezia eklenmeli

Müller 1908: des Budistischen < des buddhistischen

MW: $\quad$ A Sanskrit-English $<$ Sanskrit-English

Nobel 1937: $\quad$ Sankrittext < Sanskrittext

Nobel 1958: Sehven yazılmamış olan bu eser şu şekilde eklenebilir: NoBEL, JoHANNES: Suvarṇaprabhāsottama-Sūtra. Das Goldglanz-Sūtra. Ein Sankrittext des Mahāyāna-Buddhismus. I-Tsing's chinesische Version und ihre tibetische 
TANITMA: TOKYÜREK, HACER: Altun Yaruk Sudur IV. Tegzinç (Karşılaştırmalı Metin Yayını). Kayseri 2015, 718 s. / A. Deveci (127-132. s.)

Übersetzungen. I-Tsing's chinesische Version übersetzt, eingeleitet, erläutert und mit einem photomechanischen Nachdruck des chinesischen Textes versehen. Erster Band. Leiden 1958.

Rinpoche 1993: The Namo Buddha Seminar < Namo Buddha Publications

Röhrborn 1971: Eine Uigurische totenmesse < Eine uigurische Totenmesse. Text, Übersetzung, Kommentar

Shōgaito 1988: 56-99 sayfa numarası eklenmeli

Tekin 1976:

Uygurca Metinler II, Maytrısimit, Burkancıların Mehdisi ile buluşma Uygurca ibtidai bir dram < Uygurca metinler II, Maytrısimit, Burkancıların mehdîsi Maitreya ile buluşma Uygurca iptidaî bir dram (Burkancılı̆̆ın Vaibhāṣika tarikatine âit bir eserin Uygurcası)

Tezcan 1974: $\quad$ Deutsche Akademie der DDR < Deutsche Akademie der Wissenschaften der DDR

Uçar 2013: $\quad$ Uzerine < Üzerine

Uçar 2013a: $\quad$ Altun Yaruk Sudur < Uygurca Altun Yaruk Sudur, Usuluyle $<$ Usûlüyle

UW:

Uigurisches Wörterbuch < Uigurisches Wörterbuch. Sprachmaterial der vorislamischen türkischen Texte aus Zentralasien

Wilkens 2001: (Trikāya) < (trikāya)

Zieme 1985: $\quad$ Budistische $<$ Buddhistische

Zieme 2000: Brepols < Turnhout -Brepols yayınevi, Turnhout basım yeri, Berliner Turfantexte 20 olduğu eklenmeli

Zieme 2005: $\quad$ mit 193 Abbildungen auf 95 Tafeln < mit 208 Abbildungen auf 97 Tafeln

Atalay 1999'un, Arat 1999'un, Arat 1987'nin ve Gabain 2000’in ilk basımlarının eklenmesi, daha sonra parantez içinde tıpkıbasımlarının yazılması esere ulaşılmasını kolaylaştıracaktır.

“2. BERLIN METIN PARÇALARI” (s. 27-257) başlıklı bölümde, Berlin Brandenburg Bilimler Akademisi „Berlin-Brandenburgische Akademie der Wissenschaften“'nde bulunan 258 (önlü arkalı) parçanın RASCHMANN ve EHLERS katoloğundaki fragmanların listesi (= Konkordanz) verilmiştir. Daha sonrada bu belgelerin harf çevirisi ve yazı çevirimi yapılmıştır.

“3. ST. PETERSBURG (RM) ASIL METIN” (s. 258-466) adlı üçüncü bölümde RADLOVMALOV nüshasının yöntemler bölümündeki teknikler esas alınarak Berlin fragmanlarıyla karşılaştırmalı harf çevirisi ve yazı çevirimi yapılmıştır. Aynı zamanda metnin mevcut olan Çince karşılıkları da verilmiştir.

Metnin Türkçeye çevrildiği “4. TÜRKIYY TÜRKÇESINNE AKTARIMI” (s. 467-506) başlıklı bölümden sonra gelen " 5 . AÇIKLAMALAR" bölümünde Budist terimler, detayl bir şekilde açıklanmıştır. Budist dinî terimlerin bu şekilde ayrıntılı bir şekilde açıklanmasının yanında Çince eşdeğer metinle karşılaştırması da yapılmıştır. Çince metnin çevirisi için NOBEL'in ${ }^{13}$ Almanca tercümesinden yararlanıldığı da belirtilmiştir. Bunun yanında yabancı kökenli kelimelerin alındığı kaynak diller ve o dillerdeki şekillerine yer verilmiştir. Metne hakim olan

13 Nobel, Johannes: Suvarṇ aprabhāsottama-Sūtra. Das Goldglanz-Sūtra. Ein Sankrittext des Mahāyāna-Buddhismus. I-Tsing's chinesische Version und ihre tibetische Übersetzungen. I-Tsing's chinesische Version übersetzt, eingeleitet, erläutert und mit einem photomechanischen Nachdruck des chinesischen Textes versehen. Erster Band. Leiden 1958. 
Budist felsefenin daha iyi anlaşılabilmesini sağlayan bu bölüm araştırmacılara rehber niteliğindedir.

Cibakaya 2.3 programıyla hazırlanan çalışmanın "6. DİZiN” (s. 643-718) başlıklı son bölümünde, metinde geçen kelimeler abece sırasıyla listelenmiştir. Madde başı Türkçe değilse ilk olarak kelimenin gelmiş olduğu dil ve o dildeki şekli verilmiştir. Kelimenin Türkçesi verildikten sonra metinde hangi satırda hangi ekle birlikte ve kaç kere geçtiği yazılarak çözümlemeli dizin oluşturulmuştur. Dizin bölümüne aşağıdaki ufak değişiklikler eklenebilir:

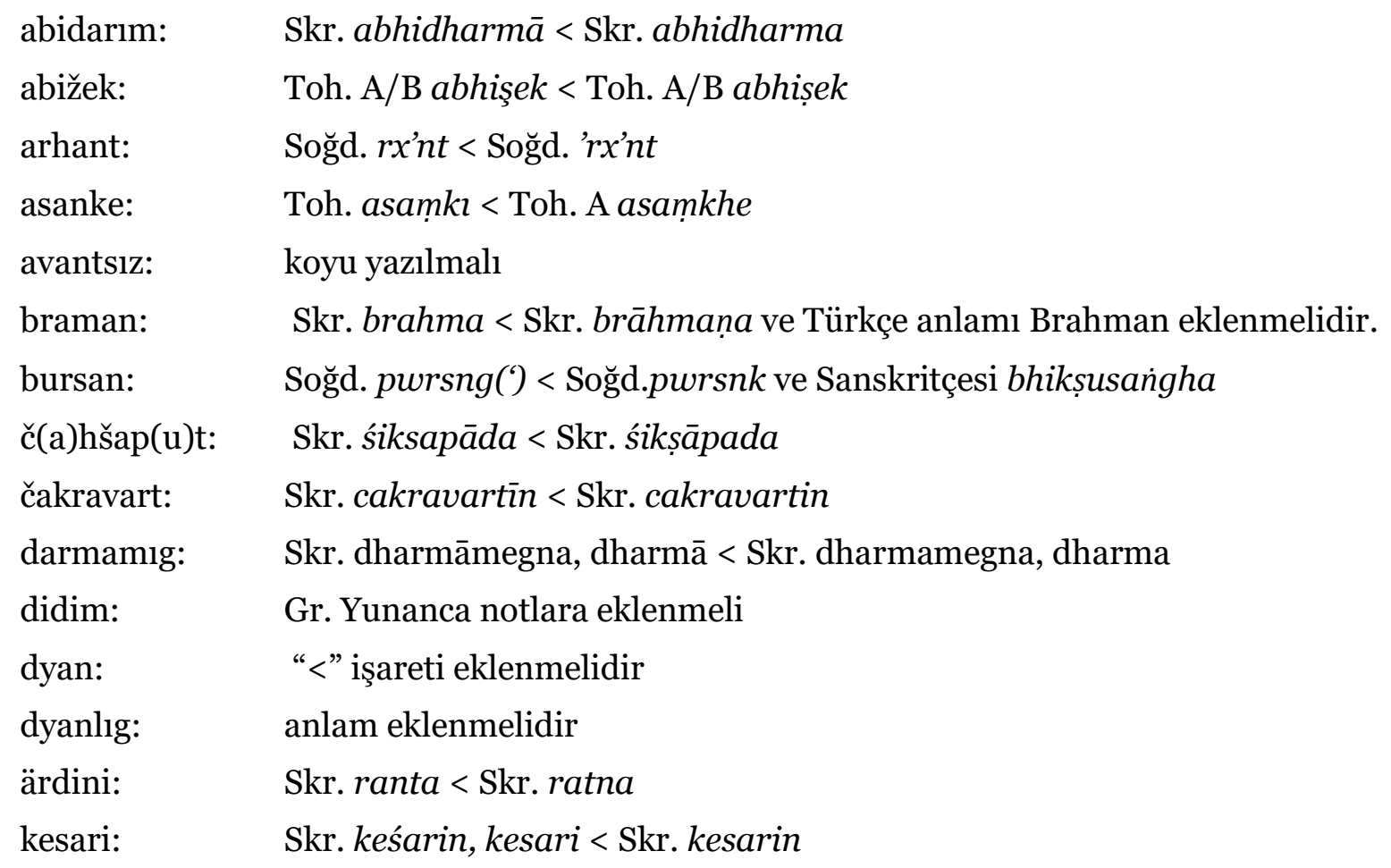

RADLOV-MALOV nüshasındaki 143 sayfayı ve Berlin'deki 258 fragmanı içeren bu oldukça uzun, anlaşılması güç, dinî akideleri ele alan metni çalışan ve kullanımımıza sunan HACER TOKYÜREK’in bu eseri, bizlere Budist felsefenin içinde önemli bir yeri olan Pāramitā'ları anlamamız için ışık tutacak bir kaynak eser niteliğindedir. Bu değerli eseri, bizlerin faydasına sunan HACER Hocamıza teşekkürü bir borç bilir ve değerli çalışmalarının devamını heyecanla bekleriz.

\section{Kisaltmalar}

$\begin{array}{ll}< & \text { önerilen } \\ \text { ET. } & \text { Eski Türkçe } \\ \text { Gr. } & \text { Yunanca } \\ \text { s. } & \text { sayfa } \\ \text { Skr. } & \text { Sanskritçe } \\ \text { Soğd. } & \text { Soğudca } \\ \text { Toh. } & \text { Toharca }\end{array}$

